\title{
"Somos artistas y somos profetas en el parque": estrategias de autorrepresentación de cuentachistes y predicadores en el Parque Centenario
}

\author{
Sindy Cardona Puello ${ }^{1}$ \\ Karen Rivera Feria
}

\section{Resumen}

Este ensayo constituye un esfuerzo por entender las prácticas culturales de los sujetos populares que tienen lugar en el parque Centenario de la ciudad de Cartagena. La narración de chistes y la predicación del Evangelio son dos de estas prácticas que, aunque han sido excluidas e invisibilizadas por el discurso hegemónico y las políticas culturales oficiales, se convierten en verdaderos performances en donde lo discursivo es fundamental para comprender las estrategias de autorrepresentación de las que se valen cuentachistes y predicadores para otorgar legitimidad a sus prácticas culturales, y al mismo tiempo les permiten comunicar sus identidades colectivas e individuales.

Palabras clave: legitimidad, performance, artistas callejeros, auto representación, subalternos, prácticas culturales.

\begin{abstract}
This essay constitutes an effort to understand popular subjects' cultural practices that take place in the Parque Centenario of Cartagena City. Jokes narration of and the gospel preaching are two of these practices that, although they have been excluded and invisibilized by the hegemonic speech and the official cultural policies, they become true performances where the discursive construction is fundamental to understand the strategies of self representation which they, joke tellers and preachers, use to grant legitimacy to their cultural practices and at the same time allow them to communicate their collective and individual identities.
\end{abstract}

Key words: legitimacy, performance, street artists, self representation, subalterns, cultural practices.

\footnotetext{
${ }^{1}$ Este ensayo hace parte del trabajo de grado de las autoras titulado Cuentachistes y predicadores en el parque Centenario: usos y sentidos del espacio público que presentaron al Programa de Lingüística y Literatura de la Facultad de Ciencias Humanas de la Universidad de Cartagena en junio de 2007. Las autoras actualmente hacen parte del Grupo de Estudios Literarios y Representaciones del Caribe (Gelrcar), semillero de investigación de Ceilika, sede Cartagena. E-mail: karencarolina_8@hotmail.com - sindycardona84@gmail.com
} 


\section{Introducción}

Son varios los estudios que desde distintas disciplinas señalan que la fragmentación, el aumento de las distancias espaciales y sociales y la rapidez del flujo son la nota predominante en el ambiente urbano de las ciudades ${ }^{2}$. Si bien esto es cierto, no podemos negar que al interior de las urbes aún se están generando espacios en los que se posibilita el encuentro, el intercambio o ciertas dinámicas de interacción que permiten la conformación de nuevas redes de amistad y de socialidad. Esto ocurre porque la ciudad no siempre corresponde con el proyecto urbanístico de los sectores políticos oficiales, sino que está a merced de los movimientos contradictorios que se compensan y se combinan fuera del poder panóptico (De Certeau, 1996).

La ciudad de Cartagena, y en especial su centro histórico, es un claro ejemplo de estos movimientos contradictorios que se generan al interior del contexto urbano. En Cartagena, pese a la existencia de un imaginario hegemónico de ciudad turística propiciado por los grupos que ostentan el poder económico, social y político, hay ciertas plazas y parques ubicados en la zona céntrica que escapan del control panóptico de esa visión hegemónica, y cuyos usos remiten a otra ciudad donde los habitantes crean sus propios lazos de relaciones con la urbe, sin importar que no correspondan con el discurso oficial. Así, por ejemplo, el parque Centenario (ubicado entre el Camellón de los Mártires, al norte y la calle de la Independencia, al sur), según el discurso oficial, es un lugar importante dentro de la historia de Cartagena, por representar un homenaje a los cien años de su independencia; incluso en sus inicios, en 1911, fue concebido como un espacio marcador de distinción social ${ }^{3}$ por parte de las élites económicas, políticas y raciales. Sin embargo, hoy día es un espacio público despojado en gran parte de toda esa carga simbólica. Ahora es un

\footnotetext{
2 Para el antropólogo Manuel Delgado (1999), la ciudad no es lo urbano. "La ciudad es una composición espacial definida por la alta densidad poblacional y el asentamiento de un amplio conjunto de construcciones estables" (23), mientras que "lo urbano es un estilo de vida marcado por la proliferación de urdimbres relacionales deslocalizadas y precarias" que puede darse o no en la ciudad.

${ }^{3}$ Cielo Puello (2005) plantea que la recuperación de las plazas y la construcción de monumentos adelantados a partir de 1911 fue uno de los hechos que significó para las élites la entrada de la ciudad en la modernidad y que, además, ponía a funcionar simbólicamente una historia contada desde las élites blancas, masculinas, donde fue negado el papel protagónico de negros, mulatos, indígenas y de las mujeres. Afirma también que ya existía el intento por parte de la élite de restringir el acceso y los comportamientos de los miembros de los grupos populares en la plaza.
} 


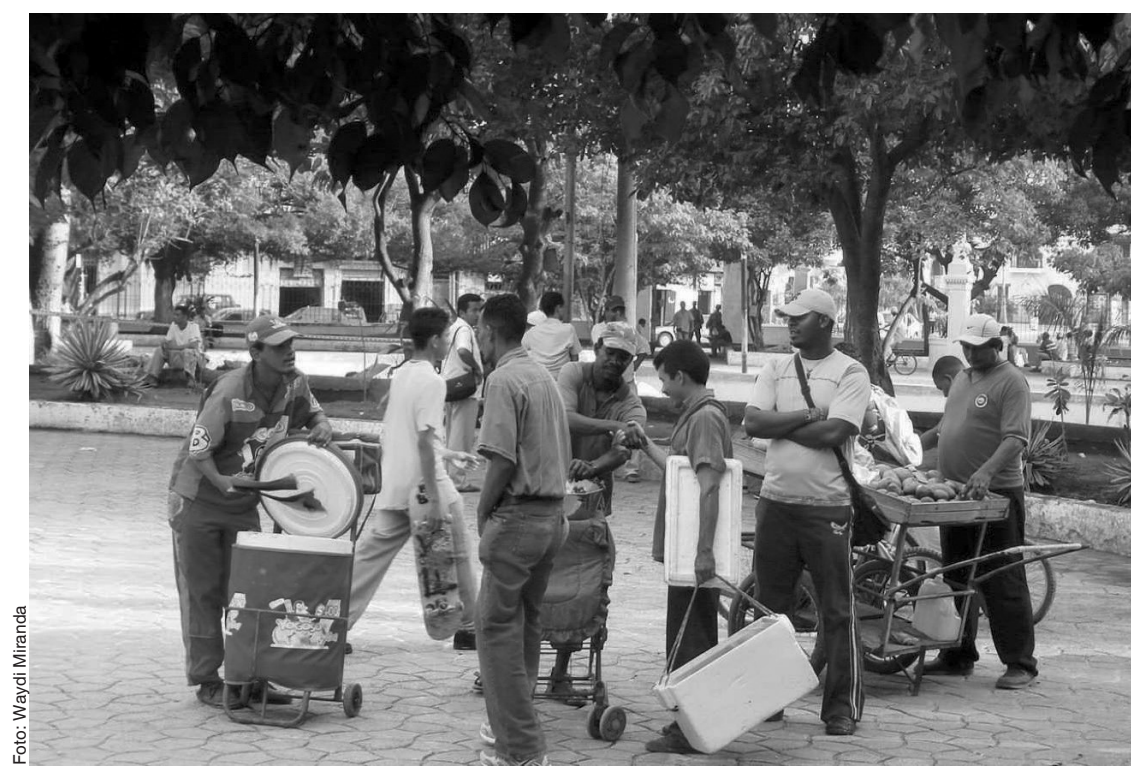

El "Uso Carruso" vende sus CDs en el parque Centenario.

parque donde concurren una variedad de actores sociales que, con sus distintos usos y prácticas, le otorgan nuevos sentidos.

De la multiplicidad de usos que se hacen del Parque Centenario nos ocuparemos aquí de dos prácticas que, lejos de tener un carácter esporádico, hacen parte de la vida o dinámicas propias del Parque y de un amplio grupo de habitantes de Cartagena. Se trata de la actuación de los cuentachistes ${ }^{4}$ y la predicación del evangelio ${ }^{5}$ que tienen lugar alrededor del Obelisco o Monumento de la Independencia en las horas de la tarde. Al atravesar el Parque Centenario -entre las 5:00 y 7:00 pm-podemos observar un ruedo formado por personas de diversa condición que por cualquier circunstancia llegan -así sea de paso- a escuchar los chistes narrados por "el Uso Carruso" y "el Cuchilla" Géles. Muy cerca de este ruedo se puede ver y escuchar a varios predicadores evangélicos que, aunque no cuentan con un público numeroso, pregonan fervientemente la palabra de Dios.

\footnotetext{
${ }^{4}$ Edgar Julio Martínez y Edelberto Geles son dos cuentachistes callejeros conocidos popularmente como el "Uso Carruso" y el "Cuchilla" Geles, respectivamente. Desde hace aproximadamente catorce años se dedican a contar chistes en varios sitios públicos de Cartagena, entre ellos el parque Centenario, lugar de origen y foco principal de su actividad.

${ }^{5}$ Dilson Alvarez y Edilsa María Arias son dos predicadores evangélicos que desde hace aproximadamente tres años anuncian la palabra de Dios en el Parque Centenario de Cartagena. Generalmente, realizan su predicación en las horas de la tarde, a pocos pasos del lugar donde los cuentachistes llevan a cabo su puesta en escena.
} 
Pese a que para la mayoría de la élite social y política de la ciudad, así como para gran parte de la comunidad académica, la presencia de humoristas ${ }^{6}$ y predicadores en el Parque puede ser un asunto sin mucha trascendencia, hemos notado que sus actividades constituyen un tipo particular de práctica social que genera sentido(s) en la vida cotidiana de muchos sujetos populares en Cartagena; son prácticas culturales que propician espacios de interacción dentro de los cuales se pueden establecer lazos de amistad entre diversos individuos que comparten algunos gustos ${ }^{7}$.

Aunque asistir al Parque a escuchar a los cuentachistes o a los predicadores son prácticas culturales importantes, no han sido abordadas aún desde un enfoque investigativo. Ni los académicos, ni los grupos de poder sociopolítico se han interesado en conocer el discurso que cuentachistes y predicadores manejan acerca de la situación en la que ellos participan. Es por ello que este ensayo se propone analizar el discurso emitido por estos actores sociales durante su performance ${ }^{8}$. El discurso que estos actores emiten sobre sí mismos y sus actuaciones, su afán de diferenciarse de otros grupos y la estructura que manejan en sus performances responden a lo que hemos denominado "estrategias de autorrepresentación". Estrategias que nos permiten entender cómo se autodefinen tales sujetos y cómo perciben a los demás.

Cuentachistes y predicadores en el Parque Centenario manejan un discurso determinado respecto de sí mismos y de las prácticas culturales de las cuales son agentes. Un discurso que deja ver, entre otras cosas, una clara toma de posición frente a otros sujetos y grupos sociales. En este sentido, encontramos que para los cuentachistes es

\footnotetext{
${ }^{6}$ Nos referimos al "Uso Carruso" y al "Cuchilla" Géles como humoristas, ya que, según Ana María Vigara Tauste (s. f.), es humorista aquel que hace uso de una clara intención de resultar "cómico" y cuya disposición se le reconoce públicamente y otros disfrutan de ella. Para la autora, hay una diferencia entre un humorista y una persona que tiene un peculiar "sentido" del humor.

${ }^{7}$ Hay que aclarar que en todo espacio de interacción los lazos de amistad creados no excluyen los conflictos. En este caso, por ejemplo, han surgido roces entre los mismos cuentachistes y roces entre cuentachistes y público.

${ }^{8}$ Según los investigadores Víctor Vich y Virginia Zabala (2004), la oralidad es un tipo de interacción social, una práctica, una experiencia que se realiza y un evento en el que se participa. En esa medida, consideran la oralidad como performance. Al entender la oralidad como performance se abandona el enfoque tradicional que presta atención exclusivamente a los signos lingüísticos o a los sonidos, para dar paso a una nueva concepción que entiende la comunicación oral como un evento que integra múltiples sentidos como la visión, el tacto, así como el baile, el canto y el cuerpo en relación con el espacio. Es en ese sentido que entendemos aquí la predicación del evangelio y la narración de chistes en el Parque Centenario como performances.
} 
muy importante la autodefinición de sus actividades como un tipo de arte. Por medio de esta referencia su actividad en el Parque, además de ser un trabajo o una forma más de rebusque para hacerle frente a las dificultades económicas, se inscribe y reclama las prerrogativas que, en general, la sociedad y el medio atribuye a los artistas.

Observando con detenimiento veremos que su actividad responde a la definición de campo propuesta por Pierre Bourdieu'. Podemos decir que estos humoristas gozan de cierto capital simbólico entre algunos sectores sociales que les permite autodenominarse como artistas de la calle, cuyas prácticas son importantes para muchos de los sujetos populares que frecuentan el Parque. El "Cuchilla" Géles y el "Uso Carruso" conformarían, junto con otros cuentachistes, el campo del humor popular en Cartagena. Al interior de dicho grupo -que estaría conformado por el "Oye Oye"10, el "Cuchilla”, el "Zorro"11, el "Mello"12 y el "Uso"-, se mantiene una jerarquía definida, se respeta la trayectoria y el repertorio de cada quien, y tal como ocurre al interior de un campo cultural, también se generan roces o disputas por obtener las posiciones dominantes. Cada cuentachistes maneja, según sus criterios, una imagen determinada y trata de mantenerla y diferenciarla con respecto a la de sus colegas. Como señala Bourdieu:

\begin{abstract}
Los participantes en un campo [...] procuran en todo momento diferenciarse de sus rivales más cercanos, a fin de reducir la competencia y establecer un monopolio sobre un determinado subsector del campo [...]. Así mismo, los participantes se esfuerzan por excluir del campo a una parte de sus colegas actuales o potenciales aumentando por ejemplo, el valor del
\end{abstract}

\footnotetext{
${ }_{9}^{9}$ Bourdieu describe los "campos" como un conjunto de relaciones de fuerza que se tejen entre los miembros de un grupo social, académico, artístico, etc., que contempla posiciones de dominación y subordinación, ante las cuales los miembros del grupo desarrollan estrategias de dominación y subversión en concordancia con unas reglas de valoraciones y legitimaciones establecidas dentro del mismo.

${ }^{10} \mathrm{El} \mathrm{"Oye} \mathrm{Oye"} \mathrm{fue} \mathrm{uno} \mathrm{de} \mathrm{los} \mathrm{primeros} \mathrm{humoristas} \mathrm{en} \mathrm{narrar} \mathrm{chistes} \mathrm{en} \mathrm{el} \mathrm{Parque}$ Centenario. Según cuentan, fue asesinado mientras salía del Parque, después de tener una riña con un gamín.

${ }^{11} \mathrm{El}$ "Zorro" es otro humorista bastante reconocido entre las clases populares. Inició contando chistes en el Parque Centenario, pero con el tiempo se trasladó a la ciudad de Barranquilla, donde ha participado en programas humorísticos de televisión como "Cheverísimo" y donde cuenta chistes en las plazas públicas.

${ }^{12} \mathrm{El}$ "Mello" es un humorista cartagenero que también ha hecho presencia con sus chistes en el Parque Centenario. En la actualidad trabaja contando chistes en la ciudad de Barranquilla, donde obtiene buenas ganancias que le permiten gozar de mejores condiciones económicas que el "Uso" y el "Cuchilla".
} 
derecho de ingreso o imponiendo cierta definición de pertenencia al mismo. (1995: 66).

Precisamente por el deseo de mantener un nombre propio y de diferenciarse frente a los demás integrantes del campo, el "Uso Carruso" es enfático al momento de dejar claro que su apodo o nombre artístico fue producto de su invención y no de "el Zorro", quien, según él, es un copiador:

- Lo creé en un sistema así, o sea como cuando la persona, o sea de vacile, yo decía ¡Uso! Y cuando me jodían era ¡Uso!, y ahí lo inventé en un disco, un disco que yo bailaba, que antes yo no cantaba los discos, sino que decía era puro Uso Carruso y la gente misma me inventó el Uso Carruso a mí. Empezó a llamarme Uso. El Zorro no es el Uso Carruso, el Zorro es un copiador.

Investigadora: ¿Por qué dice eso? ¿A él también lo conocen como el Uso?

- No, como el Zorro, sino que son personas que les gusta vacilar lo ajeno. No tiene la capacidad de inventá sus propios vaciles $^{13}$ (El "Uso Carruso". 1 de agosto de 2006).

Así, dentro del campo del humor popular cartagenero en el que actualmente el "Uso Carruso" y el "Cuchilla" Géles ocupan posiciones privilegiadas, no están ausentes las disputas entre sus miembros. Como hemos visto, estos humoristas luchan por mantener, y por qué no, aumentar el capital simbólico obtenido a través del tiempo. Capital simbólico que se traduce, por supuesto, en mayor prestigio, mayor público, y lógicamente, en mayor ingreso económico. El “Uso Carruso" y el "Cuchilla" Géles consideran que el suyo es un trabajo que no cualquier individuo se atrevería a hacer; contar chistes en un parque y hacer reír a la gente es para ellos un oficio tan importante como cualquier otro y tan artístico como las piezas dramáticas montadas por teatreros callejeros. Así, por ejemplo, se reconocen como pares culturales de Domitilo y Domitila, una pareja de teatreros llamada Carángano, que actúa en distintas plazas de la ciudad y que, en ocasiones, hace su aparición en el Parque Centenario, justo antes de la presentación de los cuentachistes.

\footnotetext{
${ }^{13}$ La transcripción de esta y todas las citas son una aproximación al habla real de los sujetos entrevistados.
} 


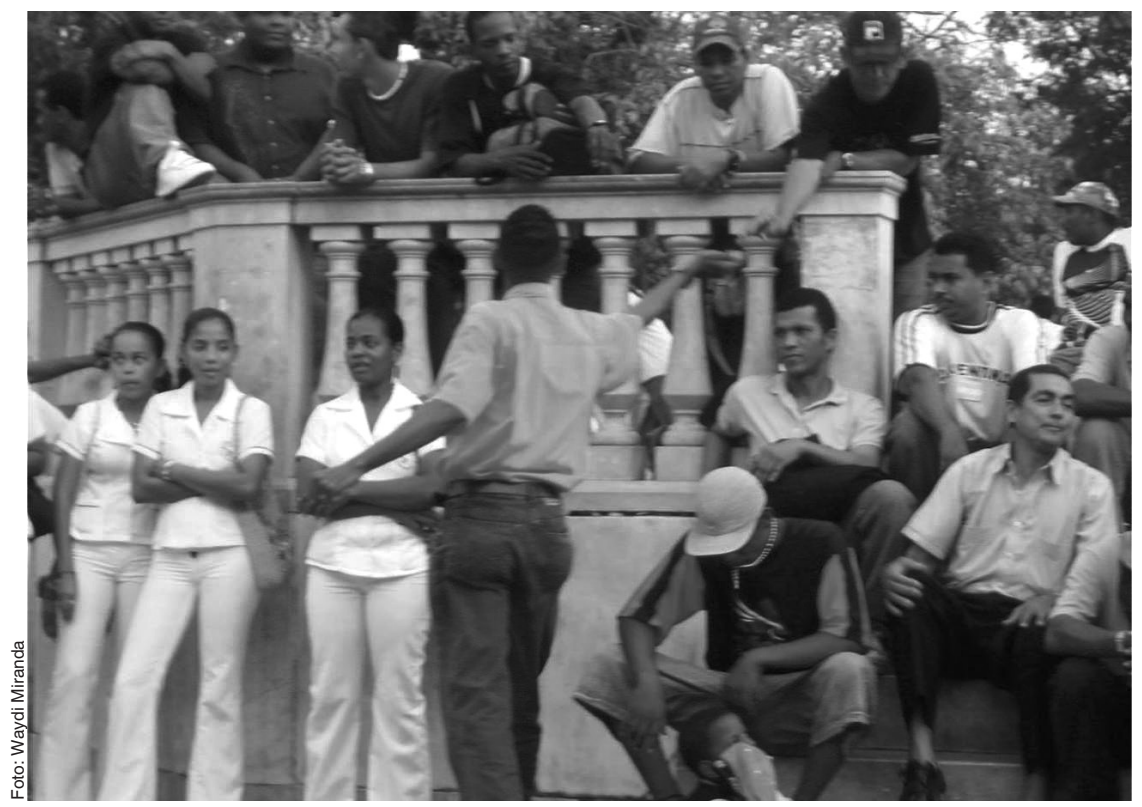

El “Uso Carruso" recogiendo dinero.

Estos personajes se consideran artistas, y esta visión parece sustentarse en la manera como está conformado el programa cuya estructura se asemeja a los formatos del show televisivo. Las implicaciones de esa autoconcepción sale a relucir durante la puesta en escena de su actividad: "Los mejores chistes están aquí. Aquí es donde se presentan los mejores espectáculos" (afirma el "Cuchilla" Géles al iniciar su presentación). El sólo hecho de que se refieran a su actividad como un programa y que le coloquen un nombre es ya de por sí muy diciente. El "Uso" y el "Cuchilla" le han dado a su programa el nombre de "Atardeceres de Risa", como forma de otorgarle legitimidad y en consonancia con la idea de que todo artista debe tener un programa "serio".

Es así como el "Uso" -quien hace las veces de presentador o animador- se encarga de acomodar al público, preparar el ambiente y hacer el preámbulo o "calentamiento" para presentar a la estrella central, el "Cuchilla" Géles, quien ha ganado este lugar por veteranía. El "Cuchilla" hace su aparición y junto con su compañero realiza un "número de planta" llamado el Show de Cristina, que consiste en elegir a una persona del público para hacerle varias preguntas sobre su vida y burlarse de sus respuestas. Luego comienza el "Cuchilla" refiriendo la tanda inicial de chistes. Después hace un breve receso para recoger dinero. Continúa el "Uso Carruso" con su repertorio, y al terminar, éste también pasa por todo el ruedo recogiendo la colaboración. Los recesos son aprovechados por los vendedores ambu- 
lantes para ofrecer sus productos al público asistente. De esta manera podemos asimilar estos breves recesos con lo que en la televisión correspondería a los comerciales. Para darle al programa un cierre digno de cualquier show, el "Uso" anuncia un mano a mano entre él y su compañero para escoger los diez mejores chistes.

La estructura del programa puede variar dependiendo de las circunstancias: del estado del tiempo, del ánimo y de la cantidad de público presente o del cansancio de los cuentachistes. Si por alguna razón el programa se debe acabar temprano, o no se puede realizar, no hay ningún tipo de problema. De igual forma, se puede improvisar jugando con los programas televisivos de moda ("Nómadas", "Bailando por un sueño", "El Desafío"), e incluir nuevos espectáculos (un joven cantante, otro que hace trucos de magia, un contorsionista, o la intervención de un mormón), puesto que se trata de un programa que todos los días se reactualiza.

La adaptación que los cuentachistes hacen de los formatos de televisión, además de reflejar el concepto que manejan de sí mismos, da cuenta de un modo particular de recepción y reapropiación de los medios masivos de comunicación ${ }^{14}$. En lugar de ser espectadores pasivos, estos personajes populares son negociadores activos de los dispositivos y medios que la oferta massmediática les proporciona, pues no se trata de un proceso pasivo de simple recepción, sino de una resignificación ligada a intereses y visiones, en este caso, la de lo popular cartagenero. Así, la noción de artista puesta en juego por los cuentachistes corresponde también, en parte, a una visión aprehendida de los medios masivos de comunicación, y como veremos, estos humoristas la han utilizado como elemento de autorrepresentación para legitimar su actividad.

Los aplausos son la mejor manera de medir el aprecio y el valor (capital simbólico) que los asistentes le otorgan a los artistas y a su programa. Estos humoristas nunca inician una tanda de chistes sin pedir un aplauso: "Cuando un artista llega a un escenario ¿cómo lo recibe un maravilloso público?" (el "Uso Carruso"). Si la ovación de los asistentes no es muy sonora los cuentachistes recurren a una estrategia de provocación ${ }^{15}$ a través de la agresión verbal para obligar al pú-

\footnotetext{
${ }^{14}$ Para mayor claridad sobre el proceso de resignificación de los medios masivos efectuado por lo sujetos populares, ver Barbero (2003).

${ }^{15}$ El Lingüista Julio Escamilla plantea que en el acto comunicativo el sujeto comunicante hace uso de determinadas estrategias discursivas con el fin de producir ciertos efectos de seducción o convicción en el sujeto interpretante. Una de esas estrategias es la provocación que, según el autor, busca efectos sicológicos que originen un cambio de conducta en el interpretante. Para mayor claridad al respecto, ver Escamilla (1998).
} 
blico a que aplauda con fuerza: "la mujer que no aplauda le gusta la arepa, el hombre que no aplauda se le moja la canoa, el niño aplaude como niño y el marica aplaude como marica" (el "Uso Carruso"). "Su maldita madre el que no aplauda" (el "Cuchilla" Géles). Todo ello, claro, dentro del ambiente de jovialidad y permisividad propiciado por la situación comunicativa de la plaza pública.

Como en el programa "Atardeceres de Risa", la presencia del público es fundamental, los cuentachistes sienten la necesidad de mantener el contacto y la atención de la audiencia, por un lado, y por el otro, de interpelarla, para hacerles ver que es bien merecido el pago que reclaman por su acto. Apoyándonos en las funciones del lenguaje propuestas por Roman Jackobson (1984), podemos decir que los cuentachistes frecuentemente hacen uso de las funciones fática y conativa del lenguaje que determinan la relación entre emisor y receptor y entre mensaje y receptor, respectivamente. Pedir aplausos y usar marcadores lingüísticos como "Párale bola de que en cierta ocasión el mundo está tan jodio de que nojoda..." ayuda a despertar y mantener el interés del público. La función conativa se hace notoria al momento de pedir la colaboración, cuando se intenta convencer con frases provocadoras como: "me pagan mi hijueputa plata", o con frases más emotivas como: "ustedes son los patrones de este programa". La prevalencia de dichas funciones del lenguaje se explica no sólo porque son muy utilizadas en la actividad publicitaria (los cuentachistes se hacen publicidad a sí mismos y a su programa), sino también porque son funciones inherentes a una situación de tipo oral.

Puede verse entonces que el orden o estructura de "Atardeceres de Risa" refleja la concepción que los actores tienen sobre sí mismos y sobre su presentación. Hay un manejo determinado del tiempo y del espacio; se provoca la expectativa del público y hay una marcada preocupación por que el programa mantenga cierta estética. No les gusta que el programa quede "flojo", puesto que se trata de un programa realizado por "profesionales del humor" y no por cualquier "artista barato" (el "Cuchilla Géles").

Edgar Julio Martínez y Edelberto Géles harían parte del campo del humor popular cartagenero (alterno al campo oficial), y como sujetos sociales pertenecientes a dicho campo, se autorrepresentan como artistas callejeros que gozan de cierto reconocimiento en Cartagena y los municipios aledaños, y que cuentan con un público seguidor. Sin embargo, debemos señalar que la constante utilización del adjetivo "callejero" denota la necesidad de aclarar que sus perfomances están por fuera de y constituyen una práctica diferente a los 
programas humorísticos de la televisión que gozan de visibilidad y legitimidad. El adjetivo "callejero" "subraya contenidos diferenciales respecto tanto de la posición socioeconómica a partir de la cual se produce la enunciación, como también del carácter formal del mismo espectáculo" (Víctor Vich, 2001: 50).

El autoreconocimiento como artistas de la calle es una manera conciente de establecer su identidad como sujetos populares, y por tanto, de develar el carácter subalterno de sus prácticas. Vich, apoyado en autores como Guha y Beverly, sostiene que la subalternidad, más que una categoría ontológica, es un concepto relacional que consiste en "un acto performativo donde los sujetos se representan a sí mismos poniendo énfasis en las relaciones de poder en las que se encuentran inscritos y conectando su vida individual con la del grupo del que se sienten parte" (Víctor Vich, 2001: 51). En esta práctica la subalternidad se construye a partir de tres características básicas como son: el uso "oral" y no "letrado" del lenguaje, que responde a la utilización de un registro informal espontáneo donde sobresalen las palabras soeces; la precaria condición socioeconómica a la que pertenecen los cuentachistes, y el espacio desde el cual se produce la enunciación. Espacio que ha sido marginado y estigmatizado por la presencia de sujetos "poco decentes" que se han apropiado del lugar.

Ahora bien, la visión de la narración de chistes como arte no rivaliza con la noción de rebusque. Los cuentachistes no desconocen que su actuación en el Parque también es un trabajo que reporta beneficios económicos; y así lo reconocen igualmente los asistentes que hacen parte del público. Leamos, por ejemplo, lo que manifestaron dos entrevistados cuando se les preguntó si estaban de acuerdo con que los cuentachistes pidieran dinero:

- Sí, claro, porque es que de todas maneras es difícil, es difícil hacer reír a una persona [...]. (Humberto Zúñiga, 23 de agosto del 2006).

- Sí, es una forma de trabajo. Es mejor que estar en las esquinas robando [...] en el caso de la Universidad donde yo estoy a ellos los tratan de vulgares, que insultan a la gente, pero no es así, ese es su trabajo, esa es la forma de hacer reír a la gente. (Náser Padilla, 24 de agosto del 2006).

Esta última cita refleja la carga de dignidad y respeto que conlleva la presentación de los cuentachistes. La gente valora el hecho de que estos personajes decidan rebuscarse recurriendo a una cualidad 
artística y haciendo reír a otros, en lugar de elegir la delincuencia, un camino que muchísimos sujetos escogen para hacerle frente a la situación socioeconómica tan apremiante que vive la ciudad de Cartagena ${ }^{16}$.

Los cuentachistes diariamente agradecen la compañía y la colaboración del público ya que es importante en la configuración del programa. El público es, al decir de ellos, su único apoyo. Pero aclaran que el dinero que los asistentes aportan es bien merecido y no una limosna, como pueden pensar algunos. De allí que, entre bromas y chanzas, el "Uso", cuando se dispone a recoger el dinero, se dirige al público con frases como: "oiga señor, no se vaya que esta mondá no es gratis. Este es un trabajo que tienen que pagar, si está mondao no se acerque". El tono jocoso con que expresa estas frases, en lugar de ofender, causa gran hilaridad dentro del público. El espectáculo ofrecido por estos humoristas no tiene un precio estipulado, y se trata simplemente de remunerar la presentación de estos personajes con lo que cada participante considere justo. Así mismo, los cuentachistes, y en especial el "Uso Carruso", aprovechan el programa para promocionar, rifar y vender sus videos que comercializan bajo el formato de CDS, cuyo precio no supera los $\$ 3.000$.

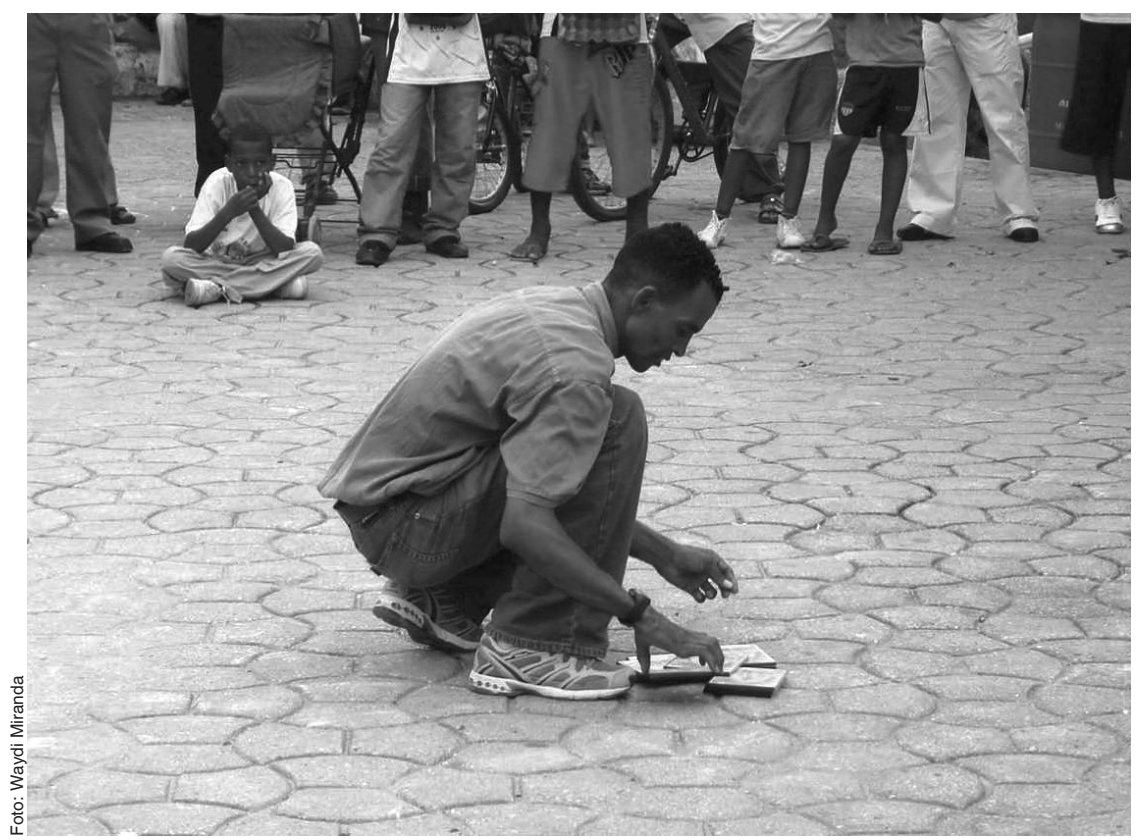

El "Uso Carruso" y los vendedores durante un receso en el parque Centenario.

${ }^{16}$ Según estadísticas del DANE, realizadas a través de la encuesta nacional de hogares, el 45\% de los hogares cartageneros están por debajo de la línea de pobreza, es decir, gana menos de dos dólares diarios para su subsistencia. DANE (2005). 
Precisamente por considerar que lo suyo es un trabajo con connotaciones artísticas, y por lo tanto digno de remuneración y prestigio, como cualquier otro, los cuentachistes y sus amigos más cercanos consideran que deberían recibir ayuda por parte de la Alcaldía y de la Gobernación, más teniendo en cuenta todos los años que llevan en este oficio:

\begin{abstract}
Si uno ya es un artista callejero tienen que apoyarlo a uno, no estrellarlo o tenerlo como menos que nadie. Para mi concepto es ese. Ya uno que hace reír a la gente durante tanto tiempo es pa' que el gobierno... ¡No esta gente hace divertí a la gente vamos a ponerle así sea un sueldo pequeñito!, cualquier cosa es cariño. Verdad, en otras partes yo digo que tienen en cuenta los actos culturales que hacen. (El "Uso Carruso", 18 de octubre del 2006).
\end{abstract}

Sin duda estas palabras ratifican lo que hemos venido diciendo acerca del modo en que se autorrepresentan los cuentachistes. Nótese que el "Uso Carruso" se refiere a sí mismo como un artista callejero, y a su práctica, como un acto cultural, lo que le da derecho a reclamar un trato especial por parte de las autoridades como recompensa por el bien que pueden estar haciendo a la sociedad. Para ellos su práctica es una forma de cultura, por lo que no debería ser desdeñada, sino más bien tenida en cuenta por la planeación y las políticas culturales del distrito.

\title{
2. El conflicto entre la autorrepresentación y la visión de otros sectores
}

Para la mayoría de los sujetos que ya tienen como costumbre ir al Parque Centenario a escuchar los chistes, el "Uso Carruso" y el "Cuchilla" Géles son, sin duda, artistas que por su talento y carisma merecen ser invitados a todo tipo de eventos. Sin embargo, hay quienes piensan que su importancia no es tanta y que sus presentaciones no pueden darse en sitios distintos de los meramente populares. Ambos personajes saben que son muy reconocidos entre las clases medias y bajas de la ciudad ${ }^{17}$, y que por eso son invitados a velorios, fiestas y a varios pueblos de la región, pero al tiempo tienen conciencia de que no son valorados en todos los espacios y que han sido relegados a un segundo plano por los circuitos oficiales de entretenimiento y de cultura en Cartagena. El 22 y 23 de Julio de 2005, por ejemplo, se realizó en la

\footnotetext{
${ }^{17}$ Pese a que la popularidad de estos humoristas es más que todo en estas clases sociales de la ciudad, en entrevistas realizadas con ellos nos comentaron que son frecuentemente invitados a fiestas realizadas por residentes de barrios como Manga y Bocagrande, y que se asombran de que los chistes más solicitados son los que ellos llaman en el Parque Centenario como chistes vulgares.
} 
ciudad una caravana de beneficencia con el fin de recoger fondos para contribuir al mantenimiento del Hospital Napoleón Franco Pareja (La Casa Del Niño). El atractivo principal era el humorista nacional José Ordóñez, quién refirió su repertorio de chistes durante treinta horas seguidas ${ }^{18}$. Llama la atención que para hacer una campaña en pro de la ciudad se recurra a humoristas de otras partes del país y no se tengan en cuenta a los humoristas populares cartageneros que son varios y de larga trayectoria. No se trata de ninguna manera de una defensa regionalista, lo que pretendemos es ilustrar una vez más la invisibilización de la que han sido objeto estos personajes.

Como ya dijimos, el "Cuchilla" Géles y el "Uso Carruso" se autodenominan artistas, sin temor a estar exagerando o estar siendo ilusos -es decir, con plena conciencia tanto de las limitaciones como de las ventajas que pueden extraer del uso de este discurso-; pero reconocen que son artistas callejeros que están por fuera del circuito mediático oficial, y que en esa medida representan lo "otro", otras formas de humor que tienen lugar en espacios marginados. Por ello, aunque ocupan posiciones dominantes en el micro-campo del humor popular cartagenero -frente a los nuevos humoristas locales-, ocupan posiciones subalternas en el campo del humor oficial colombiano -frente a José Ordóñez, por ejemplo-. Aunque graban y comercializan de manera "artesanal" sus propios CDS, aunque han participado con sus chistes en varias emisoras de la ciudad y en programas de televisión regional como La Barra (es el caso de "el Cuchilla"), aún se sienten excluidos del campo de lo que los sectores hegemónicos consideran como cultura, situación que les causa inconformismo.

\section{Cuentachistes en la prensa}

El "Uso Carruso" y el "Cuchilla” Géles han sido entrevistados por periodistas locales, pero según ellos cuentan, esas entrevistas en lugar de darlos a conocer y de ayudar a legitimar sus prácticas, lo que hacen es tratarlos de forma despectiva y tergiversar la información que ellos suministran. El 18 de junio de 2006, por ejemplo, se publicó en el diario El Universal un artículo titulado "Los asalariados del chiste" (Rubén Darío Álvarez, 2006). En dicho artículo se refieren a los cuentachistes con calificativos poco amables, y en ciertos apartes se denigra el aspecto físico de éstos. Al hablar de "el Cuchilla", el autor dice que "la vestimenta, sumamente estrafalaria y descolorida tam-

\footnotetext{
${ }^{18}$ A diferencia de los cuentachistes populares cartageneros, José Ordoñez maneja un repertorio de chistes que no incluye palabras soeces o vulgares, aunque sí hay algunos de doble sentido. Esta es quizás una de las razones por la cual goza de mayor reconocimiento ante las autoridades culturales locales.
} 
poco le ayuda", que su voz parece una "bisagra oxidada" y que "tiene el rostro más triste y atropellado que uno pueda encontrarse en el ambiente cartagenero del rebusque". Por si fuera poco, agrega que "la cara de Edgar Martínez Julio parece la clásica caricatura de un karateca oriental". Se limita a nombrar sus prácticas como actividades de rebusque y en ningún momento se les da el estatus de humoristas, dejando por fuera otros aspectos importantes, además del económico, que, como hemos visto, valen la pena ser destacados. Quizás este tipo de artículos ayude a explicar el recelo y la desconfianza de "el Cuchilla" frente a nuestro deseo de entrevistarlo. Él siente que, en cierto modo, se ha lesionado su dignidad, y como es lógico, pretende defenderse de futuras agresiones.

Para ilustrar la reacción de los cuentachistes ante la forma como han sido vistos por la prensa local, nos permitimos transcribir un fragmento de la conversación que mantuvimos con el "Uso Carruso":

Investigadora: ¿Los han estudiado otras veces? ¿Hay otra gente que ha hecho trabajos sobre ustedes?

Uso: Sí, periodistas.

Investigadora: $Y$, ¿por qué piensa que lo hacen?

Uso: Será pa' llená requisitos, requisitos es de que ajá como no tienen naa que sacá buscan cualquier argumento de cualquier persona y lo zampan en cualquier página del Universal, menos en Sucesos. ${ }^{19}$

Investigadora: 0 sea, ¿usted cree que lo entrevistan pá llená requisitos?

Uso: Sí, aro, sí, que sirva de algo, pero no pá ofendé a la gente. Investigadora: ¿Por qué los han ofendido en algún...?

Uso: Claro, ese periódico de El Universal a veces aumenta cosas que no son debidas, ya, y yo estoy de acuerdo que la persona tiene que escribir lo que está sucediendo, no aumentá cosas que no van al caso.

Investigadora: Osea, ¿que han dicho cosas que no son?

Uso: Sí, ese día nos tomaron mal, si El Universal hace como mes y medio, dijeron del Cuchilla que tomaba ${ }^{20}$ que no se qué, un poco de cosas. Vamos a poné, si usted me pide necesitamos entrevistarlo a usted, usted busca es de que una conversación

\footnotetext{
${ }^{19}$ Aquí el humorista se refiere a una página del periódico local dedicada a las noticias cuyos protagonistas son ladrones, asesinos y todo tipo de criminales que cometen actos delictivos en la ciudad.

${ }^{20}$ Es cierto (como se dice en el artículo) que "el Cuchilla" ingiere licor en el Parque Centenario y que esta costumbre ha perjudicado su voz y su salud. Sin embargo, a los cuentachistes les molesta que se publiquen este tipo de datos, puesto que transmiten una imagen de individuos irresponsables que atenta contra su dignidad como artistas.
} 
buena, que te sirva a ti y a mi; pero si usted va a hablar mal de uno, se perjudica usted y me perjudica a mí, porque la gente puede ajá, si son cosas que las van a ver a nivel nacional en toda Cartagena, en otras partes, porque ese periódico también va a otras partes.

Investigadora: Pero, ¿en ese mismo periódico también han sacado reportajes buenos de ustedes o no?

Uso: No.

Investigadora: ¿Y en otros periódicos?

Uso: No, tampoco.

Investigadora: Pero, ¿a ustedes sí les gustaría que la gente conociera su trabajo?

Uso: Claro, es bueno, pero eso no lo hacen, las cosas buenas que nos sirvan a nosotros los trabajadores de la calle no lo hacen. (17 de agosto del 2006).

Los cuentachistes saben de la importancia que tiene aparecer en la prensa local, puesto que lo que se dice en un medio de comunicación oficial es sometido a la opinión pública. Pero, así mismo, saben que si en ese medio oficial se habla mal o de forma irresponsable de ellos, la imagen que luchan por construir y mantener cada día puede verse gravemente perjudicada. Ellos son conscientes de que la prensa tiene la posibilidad como "voz autorizada" de divulgar y promover visiones de mundo. Hay entonces un conflicto entre la forma como el "Cuchilla" Géles y el "Uso Carruso" se autorrepresentan y la visión que de ellos tienen los sectores dominantes y otros sujetos. Si las autoridades y algunos ciudadanos consideraran que las actuaciones de estos personajes en el parque son prácticas culturales que representan el arte y las formas de comunicación de lo popular, no serían objeto de persecución. Tal vez sería más humano que les ayudaran a superar problemas de adicción, si los tuvieran.

\section{Predicar la palabra de Dios: un mandato divino, un mandato del cielo.}

Si los cuentachistes nombran su actividad como un programa, los predicadores evangélicos se refieren a su práctica como un "servicio", pero no un servicio de tipo comercial, que va a reportar ganancias económicas, sino un servicio espiritual, cuya máxima recompensa es pertenecer al reino que Dios tiene preparado para los elegidos. Así como Jesús laboraba para el reino de los cielos cuando predicaba en el Templo, la hermana Edilsa cree que cuando ellos predican en el Parque Centenario están "laborando en la viña del Señor" y no esperan ninguna retribución económica por parte de los asistentes, porque "el hombre no remunera, sino el que hace la remuneración es el Señor". 
Si bien hay otras formas, como el diezmo, por medio de las cuales estas organizaciones religiosas recogen dinero para su "sustento", lo cierto es que la evangelización de los predicadores en el Parque no tiene como fin obtener ganancias económicas inmediatas. La presentación de los predicadores es certificada por ellos como un servicio para Dios más que un servicio para el hombre, puesto que se trata de prestar su voz para anunciar su palabra. Dentro de su discurso es un trabajo especial, una misión que deben cumplir para alcanzar la salvación.

Frecuentemente, el hermano Dilson y la hermana Edilsa afirman que su predicación en el Parque Centenario es para que todos aquellos que transitan por este sitio tengan un encuentro con Cristo, para que no tengan excusa delante del Dios del cielo durante el Juicio Final, y para que cuando Dios les pida cuentas ellos puedan responder con tranquilidad que sí cumplieron con su misión, y que por tanto, ya se ganaron un lugar en el Cielo, lo que es para ellos su mayor recompensa:

Jesucristo va a pidí cuentas a todo el mundo, y ja mí también!... y yo abro mi boca aunque haigan poquitos que escuchen el mensaje del cielo. Dios en la balanza a mí me dice: te llamé, por qué dejaste de predicar mi palabra, por qué [...] Dios mío eso es maluco saber que venga un pez así y aah... te trague (refiriéndose a Jonás), eso es feo, eso es feo. Yo no quiero que me pase a mí, eso es feo por eso yo me paro a predicar aquí, yo no quiero que eso me pase a mí, yo no quiero que tú te mueras sin Cristo, porque Dios me pide cuentas ¡escúchame! Por eso me paro aquí bendito sea el nombre de Jesús. (Hermano Dilson, 16 de noviembre del 2006).

Según ellos el Juicio Final, en el que se ha de condenar a los pecadores y salvar a los creyentes, está próximo a llegar, porque todas las señales se están cumpliendo. En muchas de sus predicaciones sostienen que el alto desempleo, las guerras, los terremotos y las epidemias que azotan al mundo son por causa del pecado del hombre que no quiere aceptar a Cristo como su único salvador, y que la única salvación es convertirse a Jesús, para que durante su llegada no nos arroje al Infierno. Esa preocupación por anunciar lo que está por venir y por hacer que los pecadores se arrepientan imprime al discurso escatológico de estos predicadores un carácter profético, aún cuando ellos no se autorrepresenten como profetas ${ }^{21}$, sino tan sólo como

\footnotetext{
${ }^{21}$ El Profeta es un escogido y llamado por Dios para anunciarle a la gente la condición en la que se encuentra el pueblo. Los profetas anuncian el pecado del mundo y el advenimiento de un mundo nuevo.
} 
propagadores del mensaje divino, o como pescadores de hombres, a la manera de Pedro.

De otro lado, los predicadores insisten en que la vida como evangelistas implica ciertos sacrificios y dificultades que, en muchos casos, provoca el retiro de varios de sus compañeros de religión. Es así como reiteran en su discurso que el evangelio, no es una tarea fácil que cualquiera puede resistir: "El evangelio, es pa' valientes, no vaya a creer que el evangelio es fácil, el evangelio por ejemplo, el mundo, el mes de diciembre, el ambiente, las fiestas, pero el que no conoce a Cristo muy bien se aparta, pero el que es de Dios persevera hasta el fin y esos es lo que estamos haciendo nosotros aquí" (Hermano Dilson, 14 de diciembre del 2006).

Vemos entonces que así como los cuentachistes creen que su trabajo debe ser valorado, porque no son muchas las personas capaces de hacer reír a un público en una plaza, los predicadores también autovaloran su práctica al considerar que evangelizar en un parque es una tarea que requiere de mucha entrega, de gran dedicación y de un don especial que no todas las personas poseen. De igual forma, los predicadores intentan legitimar sus prácticas otorgándoles un carácter sagrado y nombrándolas como prácticas que reúnen la verdadera esencia de la vida y del comportamiento humano. Recurrir constantemente a la Biblia, auténtica fuente de verdad y de autoridad para ellos, es una forma de demostrar que la enseñanza de su doctrina es la más válida con relación a otras formas de pensamiento: "Nosotros no predicamos fábula, nosotros predicamos palabra del Dios vivo" (Edilsa Arias). Como afirma Delgado (1999), "estos movimientos de renovación religiosa tienen conciencia de ellos mismos y de la misión terrenal que, sostienen, han de llevar a cabo por mandato divino, siendo su formación y prácticas de reclutamiento procesos conscientes y deliberados"(132) .

La necesidad de legitimar su actividad conlleva a otro aspecto muy importante: el afán de diferenciarse de los llamados falsos profetas y de marcar distancia con lo mundano. Dentro del campo de la religión, en general, es muy común que una u otra corriente se autodefina como dueña de la verdad, y por tanto, merecedora de la posición dominante. Esa misma lucha se presenta en el Parque Centenario. Los predicadores evangélicos se intimidan ante la presencia de "Los Bendecidos", un grupo religioso con el que mantienen diferencias teológicas, y del que quieren distinguirse para que no haya lugar a confusiones. Al referirse a estos individuos como falsos profetas están marcando distancia, tratando de deslegitimar esa otra doctrina, 
según la cual Jesús ya está en la tierra, y de paso están defendiendo su propio capital simbólico:

Hay hombres que dicen que Jesucristo vino y esos hombres no mandan a arrepentí a sus seguidores, sino que dicen mira tú puedes fumar tú puedes robá y estás salvo, llamado el grupo de los Bendecidos, de los que dicen que están bendecidos estando en pecado. No, nadie en pecado puede estar bendecido, entonces lo que ellos tienen con nosotros es que como nosotros predicamos el evangelio, que Cristo viene, que las señales se han cumplido; más ellos dicen que sí hubo un profeta que dice que ya Cristo vino. Esa es la lucha que tienen ellos, pero nosotros no, porque nosotros no vinimos aquí a este parque sino es a predicar la palabra de Dios para que muchos se conviertan a Jesucristo. (Hermano Dilson, 14 de diciembre del 2006).

Pero los predicadores evangélicos no sólo quieren diferenciarse de los otros grupos religiosos; también les interesa marcar los límites con lo "mundano", que serían todas aquellas costumbres, formas de pensamientos y prácticas que se apartan del ideal de vida religiosa, austera y juiciosa que manejan. Dentro de las cosas profanas que condenan están, entre otras, las fiestas novembrinas, los carnavales, la forma de vestir de algunas mujeres y la narración de chistes en el Parque.

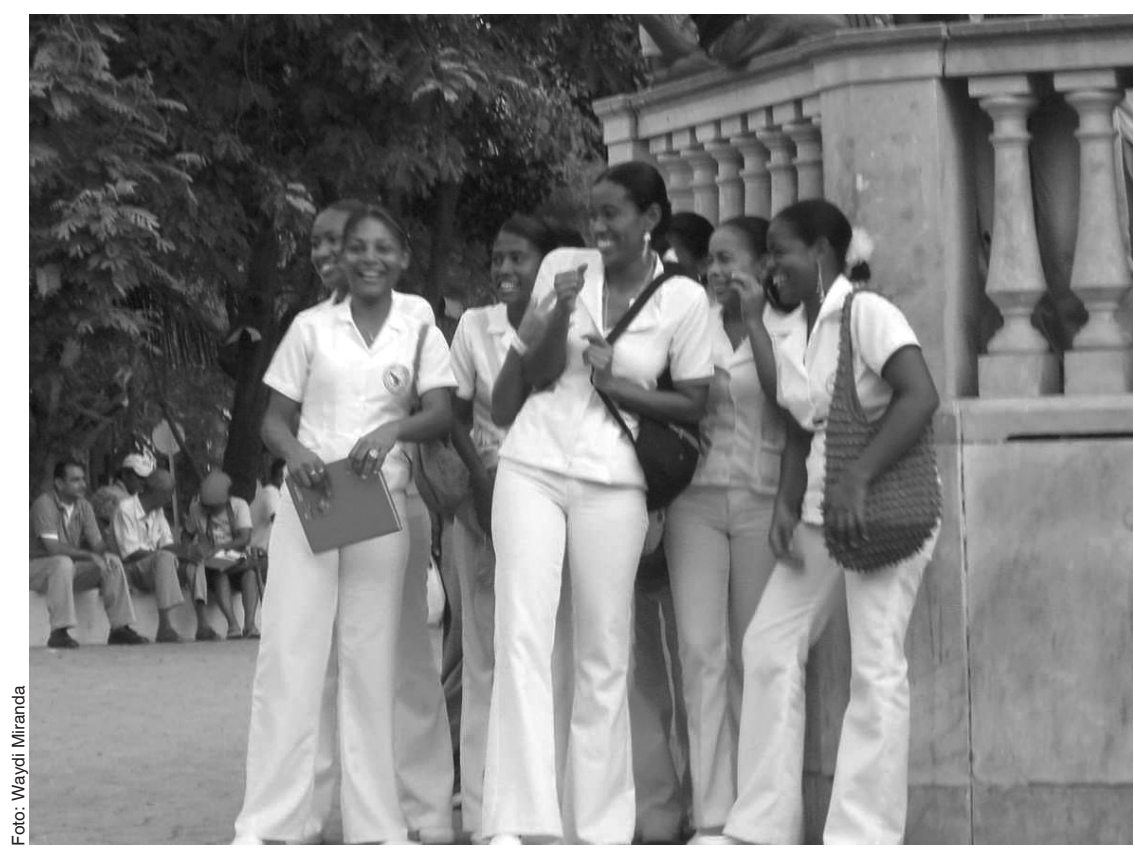

La licitud de la risa. 


\section{La licitud de la risa}

"La risa distrae, por algunos instantes, al aldeano del miedo. Pero la ley se impone a través del miedo, cuyo verdadero nombre es temor de Dios".

El nombre de la rosa.

Umberto Eco

A propósito de la narración de chistes, los predicadores (en especial el hermano Dilson) no ocultan su desacuerdo con ésta práctica y sus agentes, y esto se debe a que, por lo general, los predicadores de la iglesia cristiano-evangélica son radicales; no negocian con lo que ellos consideran prácticas pecaminosas. A diferencia de los cuentachistes, que no están interesados en mantener una disputa, los predicadores constantemente hacen alusión a los humoristas para rechazar su práctica y condenar el hecho de que la gente se aglomere alrededor de ellos y pague por unos chistes que consideran vulgares. Veamos una cita en la que, además de notarse el desacuerdo con los cuentachistes, se llega a denigrar el aspecto físico de estos personajes que "hacen parte de las cosas de este mundo", según las creencias que profesan los evangélicos:

A veces en este parque. allá, allá, allá, allá, tantos aplausos a un hombre tan maluco como ese [señalando a los cuentachistes] ¡Bendito sea el nombre de Jesús!, un hombre con la boca torcía y lo aplauden. ¡Bendito sea el nombre de Jesús!. a ese hombre tan maluco. ¡Bendito sea el nombre de Jesús! Pero aquí decimos dale un aplauso a Cristo y no hay un aplauso para Cristo ¡Bendito sea el nombre de Jesús! (Hermano Dilson, 30 de noviembre del 2006).

Recordemos aquí la visión platónica reduccionista de que lo bello es bueno y lo feo es malo. Nótese entonces cómo la fisonomía de estos cuentachistes es tomada por los predicadores, e incluso por el autor del artículo periodístico arriba comentado, como símbolo de "la fealdad moral" que sus prácticas representan. La explicación que los predicadores encuentran a la amplia preferencia del público por los chistes es que, según ellos, "el que es del mundo escucha lo del mundo, pero el que es de Dios escucha lo de Dios". Es decir, para los evangélicos es normal que la mayoría de las personas ignoren las enseñanzas religiosas y se inclinen por el pecado, puesto que la Biblia así lo predice. Así la escasez de público frente a ellos y la multitud que acompaña a los cuentachistes confirma algo que ya está escrito: "Son muchos los llamados y pocos los elegidos", así como el auto convencimiento de que ellos mismos están entre estos últimos. 
Sin embargo, sujetos como los cuentachistes se alejan de esta visión religiosa y creen que la poca presencia del público durante las predicaciones se debe más bien a razones de carácter práctico, como el gusto, el interés de la gente y la forma como los predicadores asumen la tarea evangelizadora en el Parque. La siguiente cita transmite esta percepción:

Porque es que a la gente le gusta divertirse, o sea, el modo es que, el humor relaja, [...] es que pa' uno predicá no necesita tanta bulla, uno tiene que saber predicá para que el público, el personal llegue. Pero si tú vas a predicá pa' ofendé a la gente, la gente no llega. Como acá [refiriéndose a la narración de chistes], uno no ofende a nadie, acá llega el que le gusta el humor, el que le gusta reírse, eso. (EL “Uso Carruso", 1 de agosto del 2006).

Lo cierto es que tanto cuentachistes como predicadores recurren a ciertas estrategias de aurorrepresentación para otorgarle valor o legitimidad a sus prácticas culturales. Estrategias que, por supuesto, van a estar ligadas a la visión de mundo que manejan ambos actores.

En resumen, con este apartado sobre la autorrepresentación hemos podido notar que tanto cuentachistes como predicadores manejan de manera bastante conciente un discurso sobre los performances que ellos representan, y que ese discurso constituye un esfuerzo por dotar de sentido y legitimar sus prácticas, y responde, a su vez, a la necesidad de lograr una posición dentro de su entorno social más inmediato. Se puede ver, finalmente, que tanto cuentachistes como predicadores tratan de justificar el valor de sus actuaciones, aunque de forma diferente, pues los primeros apelan a su esfuerzo personal y a su condición de artistas para demostrarles a la audiencia, a sus colegas y a la autoridad oficial que sus prácticas son importantes, mientras que los segundos descalifican las prácticas "pecaminosas" y apelan a un criterio de autoridad sagrada que no admite contraargumentación racional alguna:

Para nosotros es de gran gozo que sigamos haciendo esta labor porque al Señor le ha placido, porque el Señor nos comisionó, nos mandó para que no solamente viniéramos al Parque Centenario, sino para que vayamos a muchas partes predicando el evangelio, porque Jesús dijo id y predicad el evangelio a toda criatura porque predicar el evangelio es un Mandato Divino, un mandato del Cielo [...]. (Hermana Edilsa, 13 de diciembre del 2006). 


\section{Bibliografía}

Álvarez, Rubén Darío (18 de junio de 2006). "Los asalariados del chiste”. El Universal: Cartagena. p. 2B.

Bajtin, Mijail. (1995). La cultura popular en la Edad Media y el Renacimiento. El contexto de Francois Rabelais. Madrid: Alianza Editorial.

Borja, Jordi. (2001). "La ciudad del deseo". En Fernando Carrión. (ed.), La ciudad construida. Urbanismo en América Latina. Quito: FLACSO.

Bourdieu, Pierre. (1995). Respuestas por una antropología reflexiva. México: Grijalbo.

Canepá, Gisela. (2001). "Formas de cultura expresiva y la etnografía de lo local". En Identidades representadas. Performances, experiencia y método en los Andes. Lima: PUCP.

Casas Orrego, Álvaro León. (1994). “Expansión y Modernidad en Cartagena de Indias 18851930", Historia y Cultura, $\mathrm{N}^{\circ} 3$. Cartagena, Universidad de Cartagena, Facultad de Ciencias Humanas.

De Certeau, Michel. (1996). La invención de lo cotidiano. Artes del hacer. México: Universidad Iberoamericana.

Delgado, Manuel. (1999). El animal público. Barcelona: Anagrama.

Eco, Umberto. (2004). El nombre de la rosa. Bogotá: Casa Editorial El Tiempo.

Escamilla, Julio. (1998). "Contratos y estrategias de carácter discursivo". En Fundamentos semiolingüísticos de la actividad discursiva. Barranquilla: Universidad del Atlántico.

Freud, Sigmund. (1970). El chiste y su relación con lo inconsciente. Madrid: Alianza Editorial.

Jackobson, Roman. (1984). Fundamentos del lenguaje. Madrid: Ayuso.

Gómez B, Juan. (1981). "El chiste: una aproximación sociolingüística”. En Forma y Función. V.1. Bogotá: Universidad Nacional.

Maffesoli, Michel. (1990). El tiempo de las tribus: el declive del individualismo en las sociedades de masas. Barcelona: Icaria.

Martín-Barbero, Jesús. (2003). De los medios a las mediaciones. Bogotá: Convenio Andrés Bello.

Martínez Bermúdez, Elvis. (10 de agosto de 2005) “En el Centenario se vivió ayer un festivo diferente", El Universal, Cartagena. p. 3A

Nieves Oviedo, Jorge. (1997) "Acerca de la competencia sociocultural", Historia y cultura, $\mathrm{N}^{\circ} 5$, Cartagena, Universidad de Cartagena, Facultad de Ciencias Humanas.

(2003). Vislumbres de Caribe: Iconografías y textualidades híbridas en Cartagena de Indias. Cartagena: Observatorio del Caribe Colombiano.

Ontiveros, Diego. (s. f.). El discurso social del chiste. Recuperado de: www. argiropolis.com 
Ortiz Cassiani, Javier. (2003). “Espacio público: entre la democracia y la fragmentación. Una larga historia de trato y maltrato", Aguaita, $\mathrm{N}^{\circ}$ 9, Cartagena.

(2001). "Élite y cultura popular en Cartagena", Noventa y Nueve, $\mathrm{N}^{\circ}$ 2. Cartagena.

(2001). “Modernización y desorden en Cartagena, 1911-1930: amalgama de ritmos". En Desorden en la plaza. Modernización y memoria urbana en Cartagena. (VV. AA.). Cartagena: Instituto Distrital de Cultura.

Puello Sarabia, Cielo. (2005). La construcción de una imagen: análisis del discurso fotográfico como estrategia de auto-representación de la élite cartagenera 1900-1930. Tesis de grado no publicada. Universidad de Cartagena, Facultad de Ciencias Humanas.

Signorelli, Amalia. (1999). Antropología Urbana. Barcelona: Universidad Autónoma Metropolitana.

Silva, Armando. (2001). "Algunos imaginarios urbanos desde centros históricos de América Latina”. En Fernando Carrión (ed.) La ciudad construida. Urbanismo en América Latina. Quito: FLACSO.

Vergara, Abilio. (2001). "Espacio, lugar y ciudad: etnografía de un parque”. En Alicia Lindón, Miguel Ángel Aguilar \& Daniel Hiernaux (coords.). Lugares e Imaginarios en las metrópolis. España: Universidad Autónoma Metropolitana.

Vich, Víctor. (2001). El discurso de la calle. Los cómicos ambulantes y las tensiones de la modernidad en el Perú. Lima: Instituto de Estudios Peruanos.

Vich, Víctor \& Zabala Virginia. (2004). Oralidad y poder: herramientas metodológicas. Bogotá: Norma.

Vigara Tauste, Ana María. (s. f.). "Sobre el chiste. Texto lúdico". Recuperado de: www.ucm.es/info/especulo/numero10/chisteAhtml

Wollrad, Dorte \& Carrión, Fernando. (comp.). (1999). Introducción. La ciudad escenario de Comunicación. Ecuador: FLACSO.

Zea Solano, Arturo. (2002). "El parque Centenario: Historia y usos actuales", Palobra, $\mathrm{N}^{\circ} 3$, Universidad de Cartagena. 